\title{
AS ADVERSIDADES DOS AUXILIARES E TÉCNICOS DE ENFERMAGEM NA INSERÇÃO DO MERCADO DE TRABALHO
}

\author{
Ricardo Melquieses Campagnholi de Toledo ${ }^{1}$ \\ Kátia Aparecida dos Santos ${ }^{2}$ \\ Diego Alberto dos Santos Pinto ${ }^{3}$ \\ Alexsandro Aparecido Pérsio ${ }^{4}$ \\ Marcio Antonio de Assis ${ }^{5}$
}

\begin{abstract}
Resumo: Os profissionais de enfermagem buscam formação nas instituições de ensino que lhes proporcionam melhor preparo para atuar na assistência ao paciente. A inserção de novos profissionais em ambiente de trabalho gera desconforto tanto para os recém-contratados como para os funcionários mais antigos. A constante mudança nos diferentes contextos da atualidade, como a globalização e descentralização no ambiente hospitalar, podem gerar conflitos, se fazendo necessário que se criem estratégias para amenizar as dificuldades geradas nesse processo. Evidenciou-se falhas no processo de integração, o enfermeiro considera o acolhimento do auxiliar ou técnico de enfermagem como uma ferramenta necessária para a inserção de novos profissionais à equipe e nas rotinas institucionais. Diante das mais variadas situações, deve-se ter algum trabalho voltado a melhorar o planejamento institucional. Palavras-chave: Inserção, Experiência Profissional, Adversidades.
\end{abstract}

\footnotetext{
${ }^{1}$ Enfermagem/UMC-Universidade Mogi das Cruzes. ricardomelquieses@hotmail.com.

2 Enfermagem/UMC-Universidade Mogi das Cruzes. ka.apms@outlook.com.

3 Enfermagem/UMC-Universidade Mogi das Cruzes. diego.santop@hotmail.com.

${ }^{4}$ Enfermagem/UMC-Universidade Mogi das Cruzes. alex 01@hotmail.com.

${ }^{5}$ Enfermagem/UMC-Universidade Mogi das Cruzes. marcioassis80@gmail.com.
} 